\title{
Harnessing Defect-Tolerance at the Nanoscale: Highly Luminescent Lead Halide Perovskite Nanocrystals in Mesoporous Silica Matrixes
}

\author{
Dmitry N. Dirin, ${ }^{\dagger \dagger}$ Loredana Protesescu, ${ }^{\dagger,}$ David Trummer, ${ }^{\dagger}$ Ilia V. Kochetygov, ${ }^{\dagger}$ Sergii Yakunin $^{\dagger, \dagger}$ \\ Frank Krumeich, ${ }^{\dagger}$ Nicholas P. Stadie, ${ }^{\dagger,+}$ and Maksym V. Kovalenko ${ }^{*},+\neq$ \\ ${ }^{\dagger}$ Institute of Inorganic Chemistry, Department of Chemistry and Applied Bioscience, ETH Zürich, CH-8093 Zürich, Switzerland \\ ${ }^{\ddagger}$ Laboratory for Thin Films and Photovoltaics, Empa-Swiss Federal Laboratories for Materials Science and Technology, CH-8600 \\ Dübendorf, Switzerland
}

\section{Supporting Information}

\begin{abstract}
Colloidal lead halide perovskite nanocrystals (NCs) have recently emerged as a novel class of bright emitters with pure colors spanning the entire visible spectral range. Contrary to conventional quantum dots, such as $\mathrm{CdSe}$ and $\mathrm{InP} \mathrm{NCs}$, perovskite NCs feature unusual, defect-tolerant photophysics. Specifically, surface dangling bonds and intrinsic point defects such as vacancies do not form midgap states, known to trap carriers and thereby quench photoluminescence (PL). Accordingly, perovskite NCs need not be electronically surface-passivated (with, for instance, ligands and widergap materials) and do not noticeably suffer from photo-oxidation. Novel opportunities for their preparation therefore can be envisaged. Herein, we

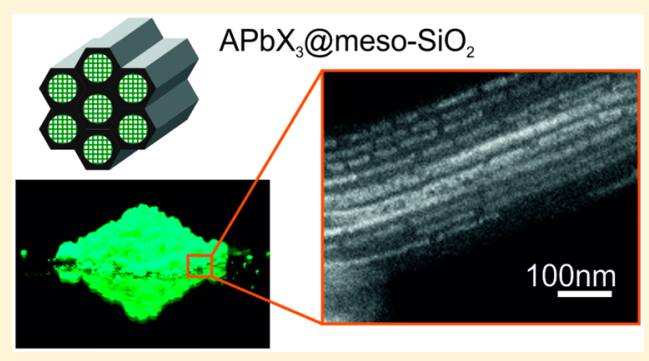
show that the infiltration of perovskite precursor solutions into the pores of mesoporous silica, followed by drying, leads to the template-assisted formation of perovskite NCs. The most striking outcome of this simple methodology is very bright PL with quantum efficiencies exceeding 50\%. This facile strategy can be applied to a large variety of perovskite compounds, hybrid and fully inorganic, with the general formula $\mathrm{APbX}_{3}$, where $\mathrm{A}$ is cesium (Cs), methylammonium (MA), or formamidinium (FA), and $\mathrm{X}$ is $\mathrm{Cl}, \mathrm{Br}, \mathrm{I}$ or a mixture thereof. The luminescent properties of the resulting templated $\mathrm{NCs}$ can be tuned by both quantum size effects as well as composition. Also exhibiting intrinsic haze due to scattering within the composite, such materials may find applications as replacements for conventional phosphors in liquid-crystal television display technologies and in related luminescence down-conversion-based devices.
\end{abstract}

KEYWORDS: perovskites, lead halides, defects, mesoporous, luminescence, nanocrystals

\begin{abstract}
olloidal cesium lead halide perovskite nanocrystals $\left(\mathrm{CsPbX}_{3} \mathrm{NCs}, \mathrm{X}=\mathrm{Cl}, \mathrm{Br}\right.$, or $\left.\mathrm{I}\right)$ have been recently shown to possess outstanding optical properties such as bright photoluminescence ( $\mathrm{PL}, \mathrm{QY}=50-90 \%)$ within a wide color gamut. ${ }^{1}$ Recent reports have concerned various aspects of both the photophysics (stimulated emission and lasing, ${ }^{2-7}$ lightemitting devices, ${ }^{8-14}$ and single-dot spectroscopy ${ }^{15-20}$ ) and chemistry (unconventional reactivity such as postsynthetic anion exchange, ${ }^{21-24} \mathrm{X}$-ray lithography, ${ }^{25}$ shape-engineering, $^{26-30}$ up-scaling and further variations of the synthesis, ${ }^{29,31-33}$ surface chemistry, ${ }^{34-37}$ and self-assembly ${ }^{38}$ ) of $\mathrm{CsPbX}_{3}$ nanostructures. Considerable attention has also been devoted to hybrid perovskites-methylammonium lead halides $\left(\mathrm{MAPbX}_{3}\right)$ and related compositions, in the form of colloidal and noncolloidal nanomaterials. ${ }^{39-53}$ A frequently reported feature of nanoscale perovskites is their outstanding PL. On the contrary, achieving bright PL with conventional semiconductor $\mathrm{NCs}$, such as CdSe, InAs, or InP, requires electronic passivation with epitaxial layers of wider-gap semiconductors. ${ }^{54-56}$ The bright PL of nanosized perovskites coincides with other phenomenal characteristics, especially outstanding photovoltaic performance characterized by power conversion efficiencies exceeding $22 \%{ }^{57-60}$ Other studies point to a very low density
\end{abstract}

of carriers $\left(10^{9}-10^{11} \mathrm{~cm}^{-3}\right)^{61-64}$ and low densities of traps $\left(10^{9}-10^{10} \mathrm{~cm}^{-3}\right),{ }^{62}$ as well as high carrier mobilities $(25-100$ $\left.\mathrm{cm}^{2} \mathrm{~V}^{-1} \mathrm{~s}^{-1}\right){ }^{61,65}$ All of these outstanding electronic and optical characteristics are highly surprising in light of the high structural disorder present in such materials, as exemplified by a high density of vacancies (up to $1 \%$ of Schottky defects), ${ }^{66}$ unusual ionic rotations, ${ }^{67-69}$ and high ionic mobilities. ${ }^{70-72}$ Normally, structural defects in semiconductors lead to a high density of corresponding defect states inside the energy bandgap, acting as trapping states.

The rare situation wherein intrinsic defects do not act as electronic trap states-so-called defect-tolerance ${ }^{65,73-80}$-is interesting theoretically and may find numerous practical applications. For methylammonium lead iodide $\left(\mathrm{MAPbI}_{3}\right)$, by far the most studied lead halide perovskite compound, the defect-tolerance of its electronic structure has been rationalized by Brandt et al. ${ }^{73}$ The valence band of $\mathrm{MAPbI}_{3}$ closely resembles that of idealized defect-tolerant character (Figure

Received: June 29, 2016

Revised: $\quad$ August 21, 2016

Published: August 23, 2016 
a

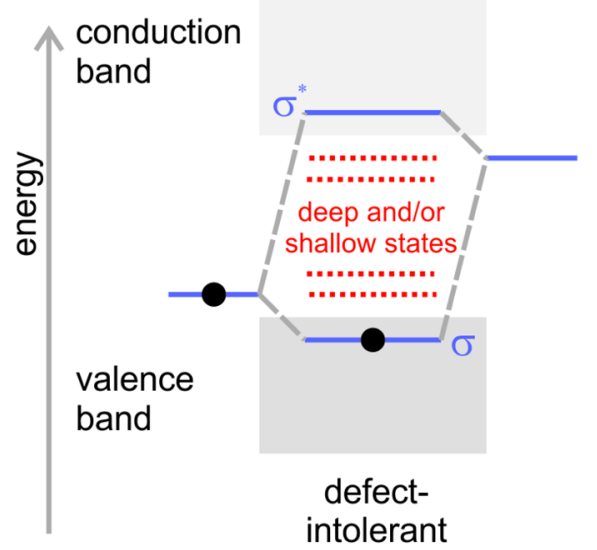

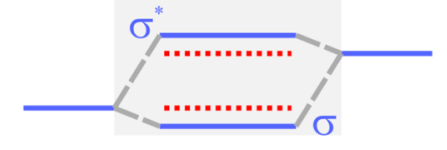

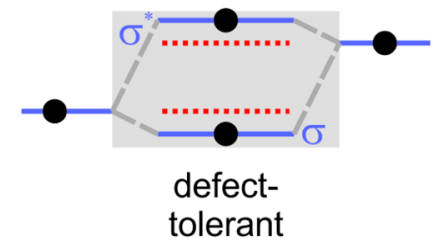

b

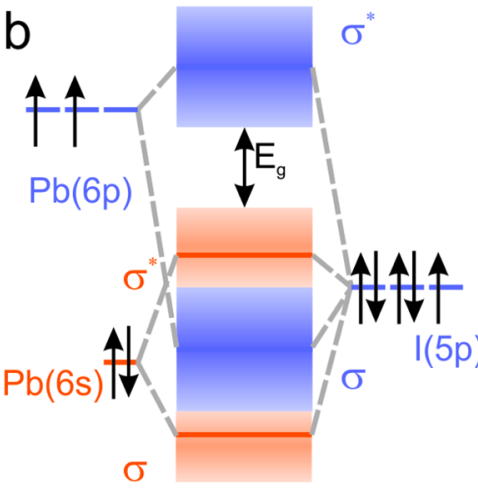

C meso- $\mathrm{SiO}_{2}$
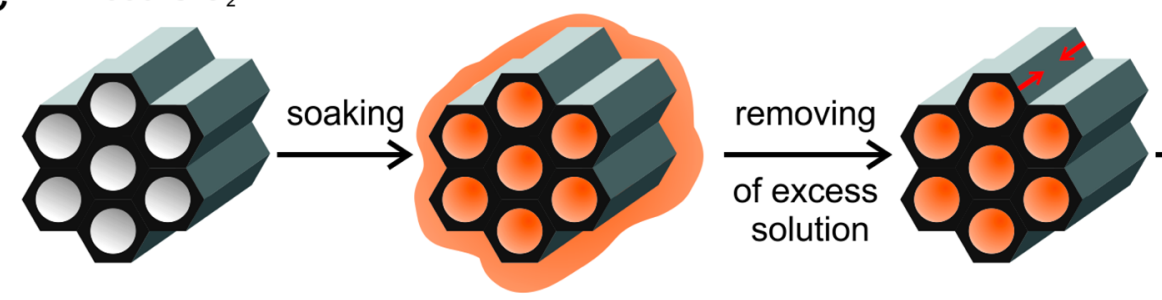

$\mathrm{APbX}_{3} @ \mathrm{meso}-\mathrm{SiO}_{2}$
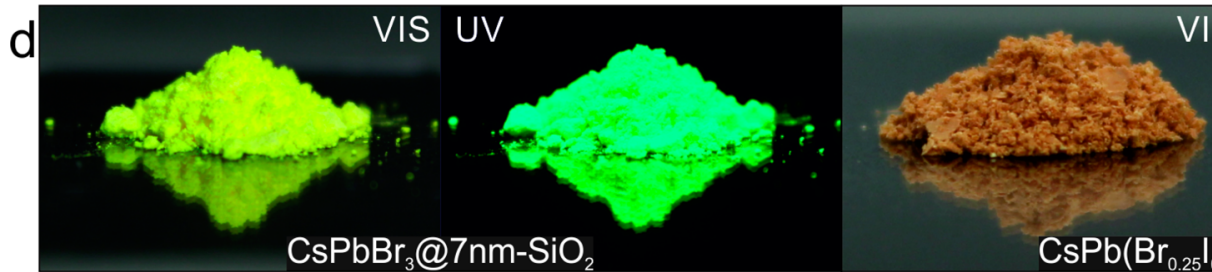

VIS UV

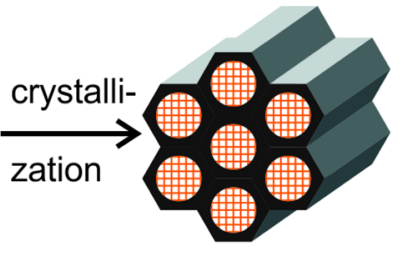

Figure 1. (a) Schematic of two limiting cases of the band-structure in semiconductors: conventional (defect-intolerant, left) and ideal hypothetical (defect-tolerant, right) (adapted from ref 69). Bonding and antibonding orbitals are identified as $\sigma$ and $\sigma^{*}$, respectively. (b) Simplified depiction of the bonding in $\mathrm{MAPbI}_{3}$, (adapted from ref 73). The valence band exhibits the desired antibonding character at its maximum, as in the ideal case in (a). (c) Schematic of the template-assisted synthesis of $\mathrm{APbX}{ }_{3} \mathrm{NCs}\left(\mathrm{A}=\mathrm{Cs}^{+}, \mathrm{CH}_{3} \mathrm{NH}_{3}^{+}(\mathrm{MA})\right.$ or $\mathrm{CH}\left(\mathrm{NH}_{2}\right)_{2}^{+}(\mathrm{FA})$; $\mathrm{X}=\mathrm{Br}^{-}$or $\left.\mathrm{I}^{-}\right)$in the pores of mesoporous silica. The mesoporous template (e.g., of characteristic pore width of 2.5, 4.0, or $7 \mathrm{~nm}$ ) is impregnated with precursor solution, followed by the removal of excess solution and finally the drying-induced crystallization of the $\mathrm{APbX}_{3} \mathrm{NCs}$. (d) Photographs of mesoporous silica impregnated with $\mathrm{CsPbBr}_{3}$ (left) and $\mathrm{CsPb}\left(\mathrm{Br}_{0.25} \mathrm{I}_{0.75}\right)_{3} \mathrm{NCs}$ (right) under daylight and under $\mathrm{UV}$ illumination.

la,b). Specifically, the maximum of the valence band is formed by the antibonding orbitals, arising from hybridization between the $\mathrm{Pb}(6 \mathrm{~s})$ and $\mathrm{I}(5 \mathrm{p})$ orbitals. The bottom of the conduction band in $\mathrm{MAPbI}_{3}$ does not meet the optimal bonding character as depicted in Figure 1a; however, strong spin-orbit effects that broaden the band play a highly beneficial role instead. This broadening shifts the bottom of the conduction band to below the $\mathrm{Pb}(6 \mathrm{p})$ atomic orbital and increases the likelihood that halide vacancies will form intraconduction band states. Thus, defects formed upon the creation of vacancies or interstitial atoms will likely appear as resonances inside the bands. Based on these considerations, surface states are also not likely to form intragap states. Correspondingly, surface ligands and other means of electronic surface passivation such as epitaxial overgrowth with protective shells are not strictly required to ensure the cleanliness of the energy bandgap and, hence, the bright PL. This explains the previously observed bright PL of $\mathrm{MAPbBr}_{3}$ particles precipitated on porous alumina. ${ }^{81,82}$ From a practical viewpoint, numerous simple synthesis methods thus can be envisaged for the production of nanocrystalline, highly luminescent perovskite NCs.

Herein, we present an investigation of the growth of perovskite $\mathrm{NCs}$ using mesoporous silica $\left(\right.$ meso- $\left.\mathrm{SiO}_{2}\right)$ matrixes as templates, showing that this can serve as a facile, complementary, noncolloidal, and ligand-free preparation route. The major finding is that this simple route allows outstanding PL, with an emission peak broadly tunable in the green to near-infrared, narrow emission line widths down to 22 $\mathrm{nm}$ in the green $(520-530 \mathrm{~nm})$ and $36 \mathrm{~nm}$ in the red $(650-$ $660 \mathrm{~nm}$ ) and high quantum yields (QY) of above $50 \%$. We note that the mesoscale templating of semiconducting NCs, especially II-VI and III-V compounds, has been well documented over the last two decades ${ }^{83-89}$ using either solution-phase or gas-phase impregnation strategies. However, bright emission from such templated conventional semiconductors was not achieved, due to the quenching effect as a result of numerous midgap states as discussed above. On the contrary, we demonstrate herein that bright PL can be achieved from perovskite NCs crystallized within the pores of mesoporous silica due to their unique defect-tolerant character.

Highly concentrated solutions of the precursor salts, AX and $\mathrm{PbX}_{2}$, were inserted into the pores (of width $2.5-50 \mathrm{~nm}$ ) of various commercially available mesoporous silica templates, exhibiting hexagonally ordered one-dimensional channels (2.5$7 \mathrm{~nm}$ pore widths), interconnected cubically ordered cavities (3 $\mathrm{nm})$, or disordered pore networks (15-50 nm pore widths) of 

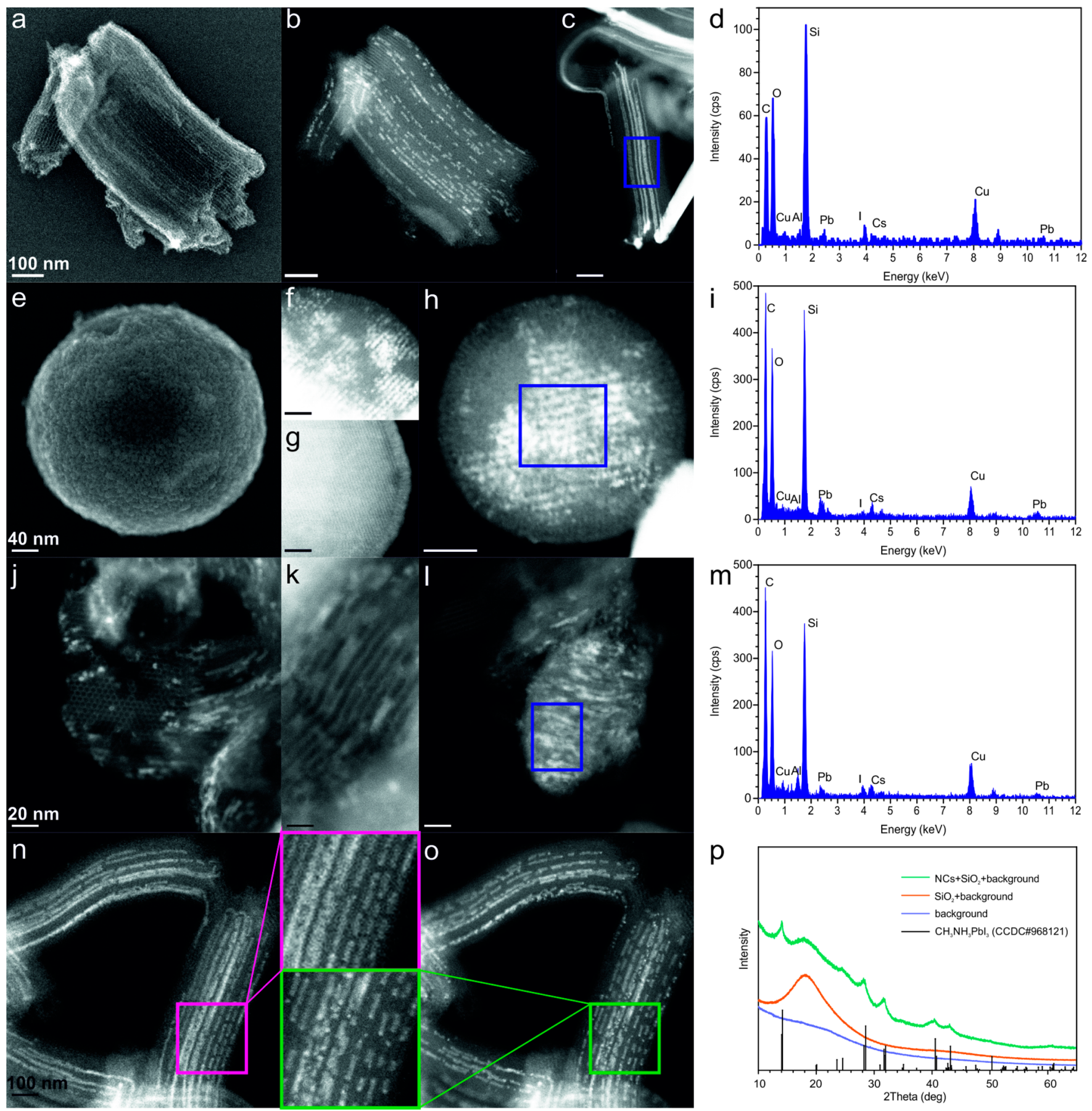

p

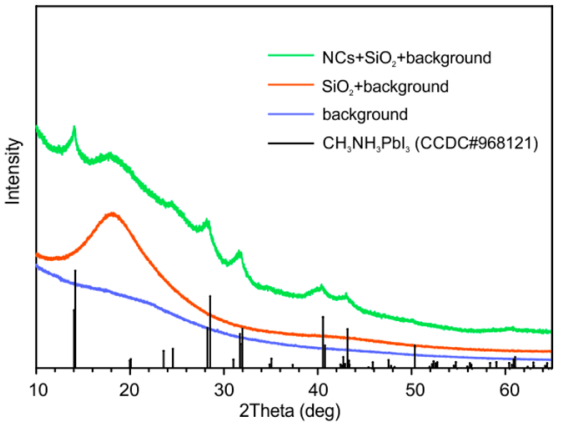

Figure 2. (a) SE-STEM and (b-c) HAADF-STEM images of a $7 \mathrm{~nm}-\mathrm{SiO}_{2}$ sample (MSU-H) partially filled with CsPbI ${ }_{3} \mathrm{NCs}$ (d) EDXS of the area highlighted in (c). (e) SE-STEM and (f, h) HAADF-STEM image of a $4 \mathrm{~nm}-\mathrm{SiO}_{2}$ sample (SBA-15) partially filled with CsPbI $\mathrm{NCs}$. For comparison, a HAADF-STEM image of pristine $4 \mathrm{~nm}-\mathrm{SiO}_{2}$ (SBA-15) is shown in (g). (i) EDXS of the area highlighted in (h). (j-1) HAADF-STEM images of $2.5 \mathrm{~nm}-\mathrm{SiO}_{2}$ (MCM-41), partially filled with $\mathrm{CsPbI}_{3}$ NCs. (m) EDXS of the area highlighted in (1). (n-o) HAADF-STEM images illustrating the effect of beam damage on $\mathrm{CsPbI}_{3} \mathrm{NCs}$ in $7 \mathrm{~nm}-\mathrm{SiO}_{2}$ (MSU-H) during (n) short and (o) long exposures. (p) XRD patterns of $4 \mathrm{~nm}$ $\mathrm{SiO}_{2}$ (SBA-15) impregnated with $\mathrm{MAPbI}_{3} \mathrm{NCs}$, along with reference patterns of the background, pristine template and bulk $\mathrm{MAPbI}_{3}$ (from the Cambridge Crystallographic Data Centre (CCDC) database).

a specific characteristic size. These matrixes were chosen among those readily available from common vendors and, after vacuum drying, were used as received. The smaller pore $(<10 \mathrm{~nm})$ templates exhibit periodically arranged, well-defined pores as a result of well-known surfactant-templated, sol-gel synthesis techniques. The larger pore silica templates employed in this work are mass produced by suppliers such as W. R. Grace \& Co. and have irregular pore morphologies of a specific characteristic pore size. Specifically, the following discussion refers to samples abbreviated as $50 \mathrm{~nm}-\mathrm{SiO}_{2}$ (irregular shaped, $0.5-2 \mu \mathrm{m}$ particles with $50 \mathrm{~nm}$ average pores), $30 \mathrm{~nm}-\mathrm{SiO}_{2}$ (irregular shaped, $20 \mu \mathrm{m}$ particles with $30 \mathrm{~nm}$ pores), $15 \mathrm{~nm}$ $\mathrm{SiO}_{2}$ (irregular shaped, $35-75 \mu \mathrm{m}$ particles with $30 \mathrm{~nm}$ pores), $7 \mathrm{~nm}-\mathrm{SiO}_{2}$ (elongated $0.5-1 \mu \mathrm{m}$ particles with hexagonally ordered 1D-channels of $7 \mathrm{~nm}$ in diameter; also known as MSU$\mathrm{H}$ mesophase), $4 \mathrm{~nm}-\mathrm{SiO}_{2}$ (200 nm spherical particles, with 


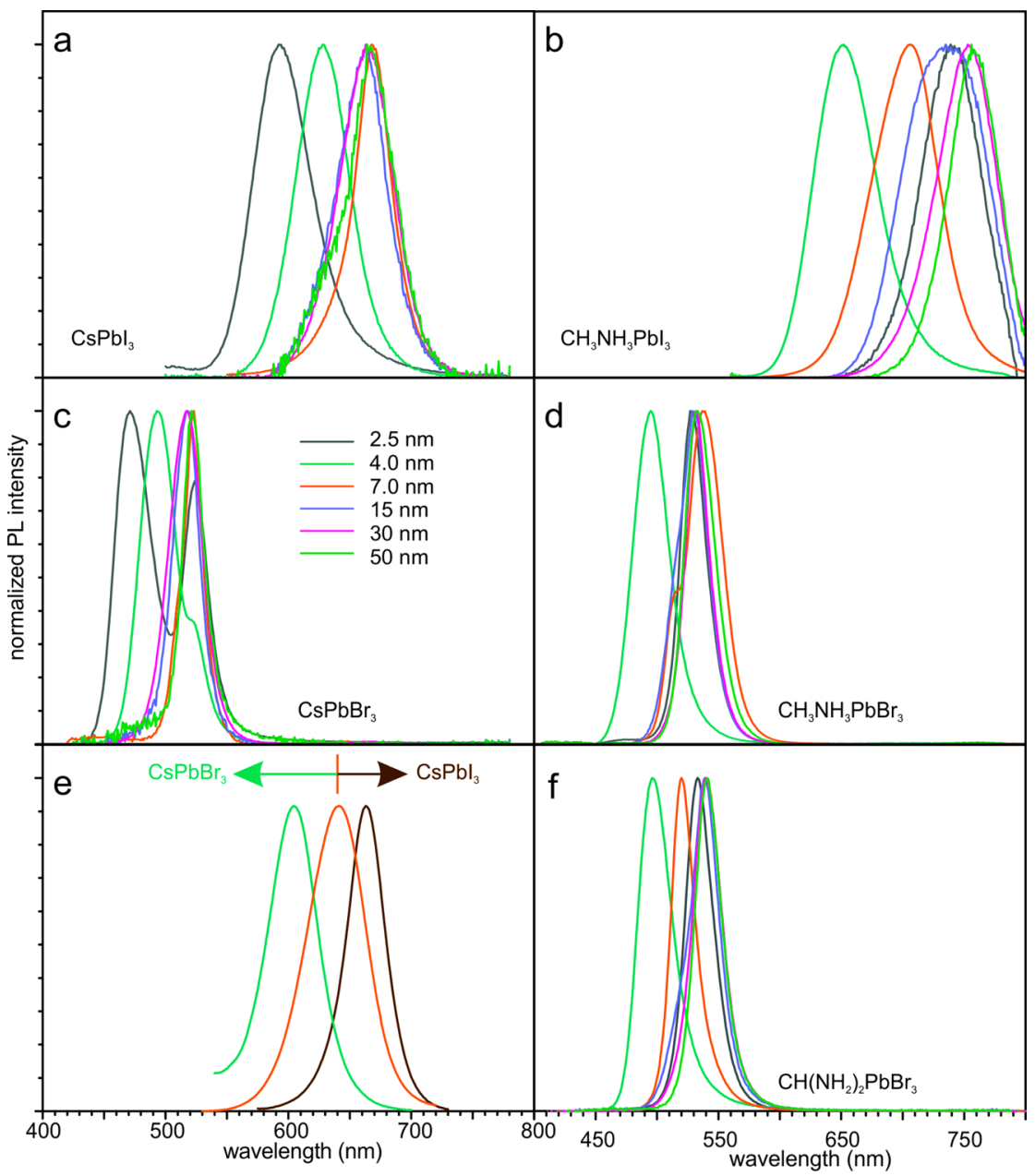

Figure 3. $\mathrm{PL}$ spectra of $\mathrm{APbX}_{3} \mathrm{NCs}$ synthesized within mesoporous silica templates of various pore sizes: (a) $\mathrm{CsPbI},(\mathrm{b}) \mathrm{MAPbI}_{3},(\mathrm{c}) \mathrm{Cs} \mathrm{PbBr}_{3},(\mathrm{~d})$ $\mathrm{MAPbBr}_{3}$, and (f) $\mathrm{FAPbBr}_{3}$. (e) PL spectra of various mixed-halide $\mathrm{CsPb}\left(\mathrm{Br}_{x} \mathrm{I}_{1-x}\right)_{3} \mathrm{NCs}$ synthesized within $7 \mathrm{~nm}-\mathrm{SiO}_{2}(\mathrm{MSU}-\mathrm{H}): x=0.4(\mathrm{green}), x$ $=0.25$ (orange), and $x=0.14$ (brown). (f) PL spectra of $\mathrm{FAPbBr}_{3} \mathrm{NCs}$ synthesized in mesoporous silica with various pore sizes.

hexagonally ordered 1D-channels of $4 \mathrm{~nm}$ in diameter; also known as SBA-15 mesophase), $3 \mathrm{~nm}-\mathrm{SiO}_{2}(<150 \mu \mathrm{m}$ particles, with cubically ordered channels forming larger cavities at connection points, pore size is $\sim 3 \mathrm{~nm}$; also known as MCM-48 mesophase), and $2.5 \mathrm{~nm}-\mathrm{SiO}_{2}(0.2-0.5 \mu \mathrm{m}$ particles with hexagonally $1 \mathrm{D}$-channels of $2.5 \mathrm{~nm}$ in diameter; also known as MCM-41 mesophase). The dry meso- $\mathrm{SiO}_{2}$ was impregnated by a concentrated precursor solution (preheated to $\sim 50{ }^{\circ} \mathrm{C}$ ) in excess with respect to the pore volume of the template. The mixture was stirred in inert atmosphere and impregnation was allowed to occur for $10 \mathrm{~min}$ at room temperature. Excess solution was then removed by damping with filter paper or by gentle vacuum filtration, thereby preventing the formation of perovskite crystals outside the pores. Finally, samples were dried under vacuum at $120{ }^{\circ} \mathrm{C}$ for $\mathrm{CH}_{3} \mathrm{NH}_{3} \mathrm{PbX}_{3}$ and $\mathrm{CH}\left(\mathrm{NH}_{2}\right)_{2} \mathrm{PbX}_{3}$ or at $150{ }^{\circ} \mathrm{C}$ for $\mathrm{CsPbX}_{3}$. During drying, the impregnated silica powder was placed between two glass cover slides in order to ensure uniform heat distribution and therefore more uniform drying (see further synthesis details in the Supporting Information and in Figure S1).

A structural analysis of several samples of meso- $\mathrm{SiO}_{2}$ (of pore sizes 7, 4, and $2.5 \mathrm{~nm}$ ) impregnated with $\mathrm{CsPbI}_{3}$ or $\mathrm{MAPbI}_{3}$ is presented in Figure 2. Scanning transmission electron microscopy (STEM) in secondary electron (SE) imaging mode of $\mathrm{CsPbI}_{3}$ within $7 \mathrm{~nm}-\mathrm{SiO}_{2}(\mathrm{MSU}-\mathrm{H})$ shows its ordered mesoporous structure consisting of one-dimensional channels separated by $\sim 2.2 \mathrm{~nm}$ thick walls (Figure 2a). Imaging in highangle annular dark field mode (HAADF-STEM) and areaselective energy-dispersive X-ray spectroscopy (EDXS) clearly illustrate partial filling of the pores with $\mathrm{CsPbI}_{3}$ (Figure $2 b-d$ ). Exposure to the electron beam often leads to the fragmentation of the NCs (Figure 2n-o). X-ray diffraction (XRD) measurements of all samples of perovskite phases grown in meso- $\mathrm{SiO}_{2}$ matrixes confirm that they consist of silica and the perovskite phase in $\mathrm{NC}$ form (exemplified by $\mathrm{CH}_{3} \mathrm{NH}_{3} \mathrm{PbI}_{3} \mathrm{NCs}$ within 4 $\mathrm{nm}-\mathrm{SiO}_{2}$ as shown in Figure 2p). The XRD reflections corresponding to the perovskite phase are significantly broadened due to the finite grain size effect. Impurities in the form of extra-pore, large-grain perovskite crystals can also be detected by HAADF-STEM and EDXS techniques (Figure S2).

Difficulties in the synthesis of $\mathrm{CsPbX}_{3}$ and $\mathrm{MAPbX}_{3} \mathrm{NCs}$ smaller than 7-8 nm and the resulting instability of such NCs are well reported topics. ${ }^{2,46}$ The template-assisted preparation of such NCs is thus a unique route to such strongly quantumconfined systems. One of the tested templates herein, $4 \mathrm{~nm}$ $\mathrm{SiO}_{2}$ (SBA-15), has a regular spherical grain morphology and grain size $(200 \mathrm{~nm}$, Figure 2e) and can be handled as a colloidal suspension. In particular, small $\mathrm{CsPbI}_{3} \mathrm{NCs}_{\text {can }}$ be rather homogeneously distributed within its porous structure throughout the entire particle (see Figure $2 \mathrm{f}-\mathrm{i}$ ). Even the 

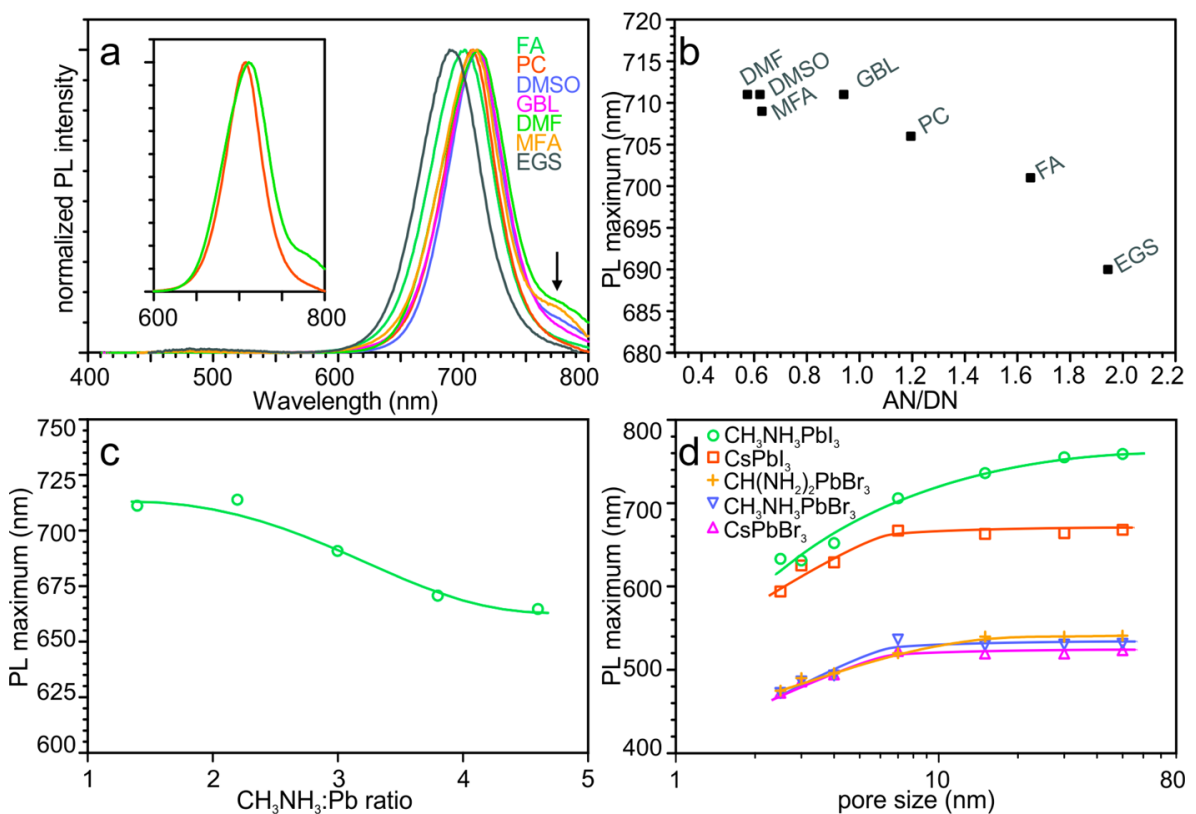

Figure 4. (a) PL spectra of $\mathrm{MAPbI}_{3} \mathrm{NCs}$ synthesized from various solvents in $7 \mathrm{~nm}-\mathrm{SiO}_{2}(\mathrm{MSU}-\mathrm{H})$ : DMF (N,N-dimethylformamide), DMSO (dimethyl sulfoxide), MFA ( $N$-methylformamide), GBL ( $\gamma$-butyrolactone), PC (propylene carbonate), FA (formamide), and EGS (ethylene glycol sulphite). An arrow indicates the PL emission corresponding to bulk $\mathrm{MAPbI}_{3}$. The inset compares the PL spectra of samples synthesized from DMF and PC. (b) PL maximum as a function of the AN/DN ratio of the solvent (where AN and DN are the acceptor and donor numbers of the given solvent, respectively). (c) PL maximum as a function of the MAI: $\mathrm{PbI}_{2}$ ratio for NCs grown from MFA in $7 \mathrm{~nm}-\mathrm{SiO}_{2}$ (MSU-H). (d) PL maximum as a function of template pore-size for various $\mathrm{APbX}_{3}$ perovskite $\mathrm{NCs}$ grown within meso- $\mathrm{SiO}_{2}$.

smallest pore template, $2.5 \mathrm{~nm}-\mathrm{SiO}_{2}$ (MCM-41), can be successfully impregnated with $\mathrm{CsPb}_{3} \mathrm{NCs}$ as shown in Figure $2 j-m$.

The template-synthesized NCs of all investigated perovskite compositions are luminescent and show pore-size-dependent $\mathrm{PL}$ spectra (Figure $3 \mathrm{a}-\mathrm{d}, \mathrm{S} 9$ ). NCs synthesized in $50 \mathrm{~nm}-\mathrm{SiO}_{2}$ emit near the bandgaps of the corresponding bulk perovskites. The emission of NCs synthesized in the smallest pore template, $2.5 \mathrm{~nm}-\mathrm{SiO}_{2}$, is $50-100 \mathrm{~nm}$ blue-shifted with respect to the bulk bandgap. Pure NCs of all studied compositions could be grown in the templates with characteristic pores sizes of $4 \mathrm{~nm}$ or above. In the case of $2.5 \mathrm{~nm}-\mathrm{SiO}_{2}$, the coprecipitation of bulk material together with $\mathrm{NCs}$ was often observed for $\mathrm{MAPbI}_{3}$, $\mathrm{CsPbBr}$, and $\mathrm{MAPbBr}_{3}$. CsPbI $\mathrm{PCs}_{3} \mathrm{NC}$, as an exception, could be synthesized in purely $\mathrm{NC}$ morphology in the $2.5 \mathrm{~nm}-\mathrm{SiO}_{2}$ template as well as those with larger pores.

Our previous investigations of colloidal $\mathrm{CsPbX}_{3}$ led to the development of techniques for the facile compositional engineering of the bandgap energy via the formation of mixed-halide solid-solutions. ${ }^{1,22}$ This possibility is also preserved within the meso- $\mathrm{SiO}_{2}$ template-assisted approach described herein, as demonstrated for mixed-halide $\mathrm{CsPb}$ $\left(\mathrm{Br}_{x} \mathrm{I}_{1-x}\right)_{3} \mathrm{NCs}$ in $7 \mathrm{~nm}-\mathrm{SiO}_{2}$ (MSU-H) in Figure 3e. This enables the possibility of multivariant (through composition and size variation) adjustment of the PL wavelength, a strategy that can be employed to target specific emitters with very high accuracy. For example, to meet the recently introduced Rec.2020 color standard, the primary red color in nextgeneration television displays should optimally emit at $630 \mathrm{~nm}$. In the cesium lead halide system, this wavelength can be reached either by $\mathrm{CsPbI}_{3} \mathrm{NCs}$ grown in $4 \mathrm{~nm}-\mathrm{SiO}_{2}$ or by $\mathrm{Cs} \mathrm{Pb}\left(\mathrm{Br}_{0.25} \mathrm{I}_{0.75}\right)_{3} \mathrm{NCs}$ grown in $7 \mathrm{~nm}-\mathrm{SiO}_{2}$ (Figure $3 \mathrm{f}$ ). However, such compositional bandgap tuning only works well for the I-rich system (red emitters), whereas further increasing the $\mathrm{Br}$ content often (although not reproducibly) leads to the partial segregation of the material into pure $\mathrm{CsPbBr}_{3}$ and I-rich mixed-halide perovskite NCs. Such a behavior is different from the colloidal synthesis of CsPb$\left(\mathrm{Br}_{x} \mathrm{I}_{1-x}\right)_{3} \mathrm{NCs}$, where a broader range of solid-solutions can be achieved. ${ }^{1}$ The phase segregation apparent in meso- $\mathrm{SiO}_{2}$ synthesized mixed-halide NCs is likely rooted in the different solubility of these compositions in the precursor solution, occurring upon drying of the solvent (bromide perovskite NCs are generally less soluble than the corresponding iodide NCs).

The potential application of perovskite NCs in television display technologies requires high color purity. Typical full width at half-maximum (fwhm) values of the PL from perovskite NCs grown by the template-assisted methods described herein are similar to those of colloidal perovskite NCs. ${ }^{1}$ For red-emitting $(\sim 630 \mathrm{~nm})$ iodide-based or mixed iodide-bromide NCs, the fwhm is $50-55 \mathrm{~nm}$. At longer wavelength $\mathrm{PL}$, the fwhm is narrower (as low as $36 \mathrm{~nm}$ ), especially for pure $\mathrm{CsPbI}_{3}$ NCs. For green-emitting bromidebased NCs, the fwhm is as small as $20-22$ at $530 \mathrm{~nm}$. This is narrower than that of state-of-the-art, commercial Cd-free NC emitters (exhibiting a fwhm of $\sim 40 \mathrm{~nm}$ ). ${ }^{90-92}$

In the evaporation-induced crystallization of $\mathrm{APbX}_{3} \mathrm{NCs}$ within meso- $\mathrm{SiO}_{2}$ described in this work, the selection of a solvent is as important as the selection of the matrix or composition of the solutes. For example, the PL spectra of 7 $\mathrm{nm}-\mathrm{SiO}_{2}$-templated $\mathrm{MAPbI}_{3} \mathrm{NCs}$ grown from a variety of organic solvents are presented in Figure 4a. The solvents exhibiting a higher solubility of perovskites, that is, $\mathrm{N}, \mathrm{N}$ dimethylformamide (DMF), $N$-methylformamide (MFA), and dimethyl sulfoxide (DMSO), lead to larger quantities of bulk perovskite deposited outside of the pores of the template, resulting in PL shoulders at longer wavelenghts. In contrast, solvents with lower solubility of the perovskites, such as 

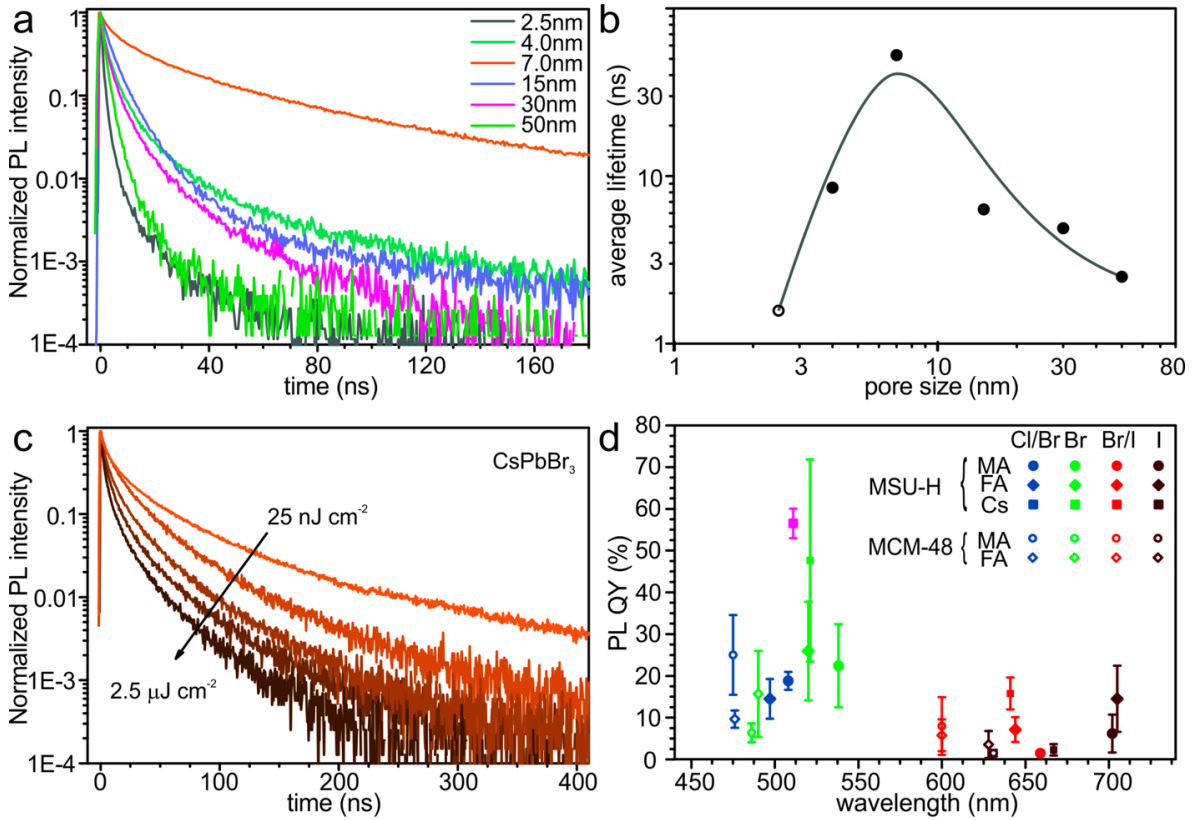

Figure 5. (a) Time-resolved PL traces for $\mathrm{CsPbBr}_{3} \mathrm{NCs}$ synthesized within meso-SiO${ }_{2}$ of different characteristic size. (b) Average $\mathrm{PL}$ lifetime as a function of pore-size of the template for $\mathrm{CsPBBr}_{3} \mathrm{NCs}$ (for the $2.5 \mathrm{~nm}-\mathrm{SiO}_{2}$ sample, emission bands from NC and bulk phases contributed to the trace and could not be separated) with a line as a guide for the eye. (c) Time-resolved $\mathrm{PL}$ traces for $\mathrm{CsPbBr}_{3} \mathrm{NCs}_{\text {synthesized within } 7 \mathrm{~nm}-\mathrm{SiO}}$ (MSU-H), with an arrow indicating the increase in pumping intensity. (d) PL quantum yield (QY) for various lead halide perovskite NCs synthesized within $7 \mathrm{~nm}-\mathrm{SiO}_{2}(\mathrm{MSU}-\mathrm{H})$ and $3 \mathrm{~nm}-\mathrm{SiO}_{2}$ (MCM-48). The orange data label for $\mathrm{CsPbBr}_{3} \mathrm{NCs}$ indicates the sample that was photoannealed for 6 days under $365 \mathrm{~nm}$ light with a fluency of $400 \mu \mathrm{W} / \mathrm{cm}^{2}$.

propylene carbonate (PC), result in samples with narrower PL spectra. The fwhm of the $\mathrm{PL}$ of $7 \mathrm{~nm}-\mathrm{SiO}_{2}$-templated $\mathrm{MAPbI}_{3}$ NCs is broader when DMF was the solvent $(65 \mathrm{~nm})$ than with PC $(53 \mathrm{~nm})$. The systematic difference in PL peak position between different solvents can be as high as $20 \mathrm{~nm}$ (Figure 4a), whereas standard sample-to-sample deviation is just $2-3 \mathrm{~nm}$. Favorable wetting or higher solubility could explain more complete pore filling and therefore larger NC size. However, no convincing correlation between the PL maximum and either the solvent's surface tension or with perovskite solubility could be found in samples investigated herein (Figures S4 and S5). Instead, the PL maximum correlates more evidently with the solvent's ability to solvate cations. The dependence of the PL maximum on the ratio of the solvent's acceptor number (AN) to donor number $(\mathrm{DN})$ is shown in Figure $4 \mathrm{~b}$. These numbers represent Lewis acidity and basicity, respectively. Solvents with a higher $\mathrm{AN} / \mathrm{DN}$ ratio solvate $\mathrm{MA}^{+}$cations less efficiently and increase their activity. The same effect (achieving higher $\mathrm{MA}^{+}$ activity) can be directly accomplished simply by increasing the concentration of this cation. Indeed, even more pronounced PL peak tuning can be realized when the $\mathrm{MAI}: \mathrm{PbI}_{2}$ ratio is varied (Figure 4c).

Previous studies have shown that colloidally synthesized, ligand-capped perovskite NCs lose their colloidal stability at sizes above $15-20 \mathrm{~nm},{ }^{1,51}$ attributed to strong dispersive interactions leading to aggregation. On the other hand, very small NCs are too labile for isolation and purification, showing a propensity for crystal phase transitions, shape changes, and aggregation. ${ }^{20}$ Hence, there have been no systematic studies on the size-dependence of optical properties at small sizes (below $8 \mathrm{~nm}$ ). Template-assisted synthesis, in contrast, opens this possibility in a straightforward manner. The correlation between peak values of PL spectra (Figure 3) and characteristic $\mathrm{NC}$ size (Figure 4d) are determined herein for $\mathrm{MAPbI}_{3}$,
$\mathrm{CsPbI}, \mathrm{MAPbBr}_{3}$, and $\mathrm{Cs} \mathrm{PbBr}_{3}$. Significant size-dependent effects are apparent for NCs synthesized within the pores of 2.5 $\mathrm{nm}-$, $4 \mathrm{~nm}$-, and $7 \mathrm{~nm}-\mathrm{SiO}_{2}$, whereas this effect is weak (e.g., in the case of $\mathrm{MAPbI}_{3}$ ) or absent for samples in larger pore templates.

Time-resolved PL spectra from template-synthesized $\mathrm{CsPbBr}_{3} \mathrm{NCs}$ show a large, nonmonotonic variation of the decay rate with pore-size (Figure 5a). NCs synthesized within 7 $\mathrm{nm}-\mathrm{SiO}_{2}$ show a significantly slower PL decay rate compared to both smaller and larger NCs. The long average lifetime of these NCs (Figure 5b) is accompanied by the highest brightness (with $\mathrm{PL} \mathrm{QY}=48 \pm 24 \%$ ) among all templated $\mathrm{CsPbBr}_{3}$ NCs. This correlation, along with an almost monoexponential PL decay, indicates that $7 \mathrm{~nm}-\mathrm{SiO}_{2}$-templated $\mathrm{NCs}$ are impacted the least by nonradiative pathways of excitonic relaxation. The measured lifetimes of $\mathrm{CsPbBr}_{3} \mathrm{NCs}$ in $7 \mathrm{~nm}-\mathrm{SiO}_{2}$ are noticeably longer than for colloidally synthesized $\mathrm{CsPBr}_{3}$ NCs (Figure S6). Taking into account the cylindrical pore geometry of the $7 \mathrm{~nm}-\mathrm{SiO}_{2}$ (MSU-H) template, this finding is consistent with previously reported shape-dependent PL lifetimes of colloidal NCs, ranging from several to tens to hundreds of nanoseconds as the shape is changed from small, nearly isotropic NCs to long $1 \mathrm{D}$ and large $2 \mathrm{D}$ NCs. ${ }^{29}$ At the same time, small $2 \mathrm{D} \mathrm{Cs} \mathrm{PbBr}_{3} \mathrm{NC}$ platelets exhibit PL lifetimes of a few nanoseconds, similar to the small, nearly cubic NCs. ${ }^{28}$ Together, these results imply that the PL lifetime of $\mathrm{CsPBr}_{3}$ NCs increases when quantum confinement is drastically reduced in one or two dimensions. None of the templated $\mathrm{CsPbBr}_{3} \mathrm{NC}$ samples show a noticeable difference in PL lifetimes under varying pumping intensities in the range of 0.25 to $25 \mathrm{~nJ} \cdot \mathrm{cm}^{-2}$. Only at excitation intensities above $25 \mathrm{~nJ} \cdot \mathrm{cm}^{-2}$, faster radiative lifetimes were observed (Figure 5c). In this respect, there is again a difference between templatesynthesized (elongated) and colloidally synthesized (cubic) 
$\mathrm{CsPbBr}_{3}$ NCs (Figure S6). Templated NCs rather resemble the behavior of colloidal $\mathrm{MAPbBr}_{3}$ nanowires ${ }^{51}$ or compact films of colloidal $\mathrm{MAPbBr}_{3}$ and $\mathrm{CsPbBr}_{3}$ NCs. ${ }^{2,51}$ The latter examples also exhibited a strong relationship between radiative lifetime and pumping intensity, which can be explained by effective exciton delocalization and the higher probability of effects of excitonic interaction (e.g., trions and multiple exciton formation) under high pump intensity within the individual nanowire. Because the number of excitons increases with pumping fluency, the relaxation becomes faster due to additional multiexciton- and charged-exciton-(trion)-related relaxation pathways with short decay times: nonradiative (Auger recombination) and radiative (coherent emission).

All template-synthesized $\mathrm{APbX}_{3} \mathrm{NCs}$ show bright $\mathrm{PL}$ under UV-excitation. For the samples emitting in the visible range, in particular in green, luminescent glowing can be clearly seen by eye even in daylight. The accurate measurement of PL QY is complicated due to strong scattering in the powders (Figure $5 \mathrm{~d})$. The wide standard deviation is mostly reflective of measurement accuracy rather than sample-to-sample variation. Despite this fact, the measurement systematically shows that templated NCs of bromide perovskites, $\left(\mathrm{CsPbBr}_{3}, \mathrm{FAPbBr}_{3}\right.$ and $\mathrm{MAPbBr}_{3}$ ) are brighter than analogous iodides (Figure $5 \mathrm{~d}$ ). This is similar to the case of colloidal lead halide perovskite $\mathrm{NCs}^{1}$ and consistent with time-resolved (TR) PL data. The average ( $48 \pm 24 \%$ ) and highest ( 90\%) measured PL QYs of $\mathrm{Cs} \mathrm{PbBr}_{3} \mathrm{NCs}$ synthesized in $7 \mathrm{~nm}-\mathrm{SiO}_{2}$ are comparable to the PL QYs of films of colloidal CsPbBr ${ }_{3}$ NCs, where QYs of 50$60 \%$ are only achievable with a very high content of excessive ligands. Meso- $\mathrm{SiO}_{2}$-templated $\mathrm{CsPbBr}_{3}$ and hybrid perovskite NCs also retain the same high QY after 6 days of photoannealing under the UV lamp (365 nm, $\left.400 \mu \mathrm{W} / \mathrm{cm}^{2}\right)$. Changes in the TR PL traces were not even observed after pulsed irradiation for $30 \mathrm{~min}$, which corresponds to $10^{10}$ laser shots with an intensity of $2 \mu \mathrm{J} / \mathrm{cm}^{2}$ (Figure S7). We emphasize that such high QYs and photostabilities are obtained for unpassivated semiconductor NCs. We are not aware of any previous templated growth of bright NCs for II-VI, IV-VI, and III-V semiconductors.

The improved processability of perovskite NCs via a template-assisted strategy might be useful in numerous applications. Large silica particles are not dispersible in solvents. Some polar solvents (e.g., MFA) are able to suspend silica particles but also completely dissolve perovskite NCs. We have found that some commonly known detergents may help to disperse silica microparticles in toluene without an effect on the perovskite NCs and their PL properties. These detergents give good dispersions for all meso- $\mathrm{SiO}_{2}$ templates investigated with mean particle sizes below $2 \mu \mathrm{m}$, such as $2.5 \mathrm{~nm}-\mathrm{SiO}_{2}$ (MCM41), $4 \mathrm{~nm}-\mathrm{SiO}_{2}$ (SBA-15), and $7 \mathrm{~nm}-\mathrm{SiO}_{2}$ (MSU-H). Simple conformable detergents like octadecylsilane (ODS) or octadecyltrimethoxysilane (OTMS) help to partially disperse silica particles in toluene without a noticeable drop in PL brightness even after a few days. Interestingly, bis(2-ethylhexyl) sulfosuccinate (also known as docusate or AOT) can disperse silica microparticles completely and very quickly. Such suspensions are stable toward ultrasonication and stay well dispersed for hours after sonication (Figure 6a). This permits the mixture of perovskite-impregnated silica microparticles with toluene-soluble polymers such as polystyrene and the preparation of uniform films as demonstrated in Figure $6 \mathrm{~b}$. Such films show bright PL and have intrinsic haze, a potentially

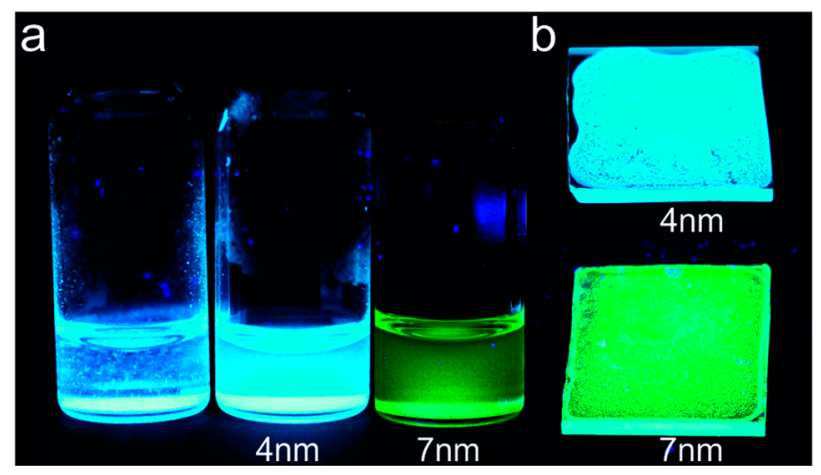

Figure 6. (a) Photographs of suspensions of (left) as-prepared particles of $4 \mathrm{~nm}-\mathrm{SiO}_{2}$ (SBA-15, $200 \mathrm{~nm}$ in diameter) impregnated with $\mathrm{Cs} \mathrm{PbBr}_{3} \mathrm{NCs}$ in toluene and (middle) after treatment with AOT, and (right) particles of $7 \mathrm{~nm}-\mathrm{SiO}_{2}$ (MSU-H, $0.5-1 \mu \mathrm{m}$ in size) impregnated with $\mathrm{CsPbBr}$ NCs. (b) Photographs of films prepared from AOT-stabilized suspensions of $4 \mathrm{~nm}-\mathrm{SiO}_{2}$ and $7 \mathrm{~nm}-\mathrm{SiO}_{2}$ impregnated with $\mathrm{CsPbBr}_{3}$ NCs. All photographs are taken under UV $(365 \mathrm{~nm})$ illumination.

useful attribute for applications such as backlight sources in television displays. ${ }^{93}$

In summary, the use of mesoporous silica templates allows the inexpensive and scalable preparation of lead halide perovskite NCs. Owing to the intrinsic tolerance of the electronic structure to the defects in these compounds, the resulting templated NCs exhibit an unprecedented high quality of PL. This result stands in striking contrast to conventional semiconductors (e.g., CdSe, InP, etc.) whose PL properties deteriorate upon incorporation within a porous matrix via trapping on surface defects, except when they are rigorously surface-passivated. Future work should be performed using other mesoporous matrixes, especially those which exhibit electrical conductivity (e.g., transparent conductive oxides, porous silicon, etc.), as well as other infiltration methods (such as consecutive ion absorption or from melts and vapors, due to the low melting point of most perovskites).

\section{ASSOCIATED CONTENT}

\section{S Supporting Information}

The Supporting Information is available free of charge on the ACS Publications website at DOI: 10.1021/acs.nanolett.6b02688.

Materials and synthetic details; additional TEM images; dependence of PL on solvent properties; TR PL of colloidal $\mathrm{Cs} \mathrm{PbBr}_{3} \mathrm{NCs}$ and template-synthesized $\mathrm{CsPbI}_{3}$ NCs; PL decay stability. (PDF)

\section{AUTHOR INFORMATION}

\section{Corresponding Author}

*E-mail: mvkovalenko@ethz.ch.

\section{Author Contributions}

(D.N.D. and L.P.) These authors contributed equally. The manuscript was written through contributions of all authors. All authors have given approval to the final version of the manuscript.

\section{Notes}

The authors declare no competing financial interest. 


\section{ACKNOWLEDGMENTS}

We thank the European Union for financial support via ERC Starting Grant 2012 (Project NANOSOLID, GA No. 306733) and a Marie Curie Fellowship (IIF-GA-2012-330524).

\section{REFERENCES}

(1) Protesescu, L.; Yakunin, S.; Bodnarchuk, M. I.; Krieg, F.; Caputo, R.; Hendon, C. H.; Yang, R. X.; Walsh, A.; Kovalenko, M. V. Nano Lett. 2015, 15 (6), 3692-3696.

(2) Yakunin, S.; Protesescu, L.; Krieg, F.; Bodnarchuk, M. I.; Nedelcu, G.; Humer, M.; De Luca, G.; Fiebig, M.; Heiss, W.; Kovalenko, M. V. Nat. Commun. 2015, 6, 8056.

(3) Wang, Y.; Li, X.; Song, J. D.; Xiao, L.; Zeng, H.; Sun, H. Adv. Mater. 2015, 27 (44), 7101-7108.

(4) Gu, Z.; Wang, K.; Sun, W.; Jinakai, L.; Liu, S.; Song, Q.; Xiao, S. Two-photon pumped lead halide perovskite nanowire lasers. 2015, arXiv:1510.03987. arXiv.org e-Print archive. http://arxiv.org/abs/ 1510.03987 (accessed July 2016).

(5) Wang, Y.; Li, X.; Zhao, X.; Xiao, L.; Zeng, H.; Sun, H. Nano Lett. 2016, 16 (1), 448-453.

(6) Eaton, S. W.; Lai, M.; Gibson, N. A.; Wong, A. B.; Dou, L.; Ma, J.; Wang, L.-W.; Leone, S. R.; Yang, P. Proc. Natl. Acad. Sci. U. S. A. 2016, 113 (8), 1993-1998.

(7) Xu, Y.; Chen, Q.; Zhang, C.; Wang, R.; Wu, H.; Zhang, X.; Xing, G.; Yu, W. W.; Wang, X.; Zhang, Y.; Xiao, M. J. Am. Chem. Soc. 2016, 138 (11), 3761-3768.

(8) Song, J.; Li, J.; Li, X.; Xu, L.; Dong, Y.; Zeng, H. Adv. Mater. 2015, 27 (44), 7162-7167.

(9) Zhang, X.; Lin, H.; Huang, H.; Reckmeier, C.; Zhang, Y.; Choy, W. C. H.; Rogach, A. L. Nano Lett. 2016, 16 (2), 1415-1420.

(10) Li, X.; Wu, Y.; Zhang, S.; Cai, B.; Gu, Y.; Song, J.; Zeng, H. Adv. Funct. Mater. 2016, 26 (15), 2435-2445.

(11) Li, G.; Rivarola, F. W. R.; Davis, N. J. L. K.; Bai, S.; Jellicoe, T. C.; de la Peña, F.; Hou, S.; Ducati, C.; Gao, F.; Friend, R. H.; Greenham, N. C.; Tan, Z.-K. Adv. Mater. 2016, 28 (18), 3528-3534.

(12) Palazon, F.; Di Stasio, F.; Akkerman, Q. A.; Krahne, R; Prato, M.; Manna, L. Chem. Mater. 2016, 28 (9), 2902-2906.

(13) Zhang, X.; Xu, B.; Zhang, J.; Gao, Y.; Zheng, Y.; Wang, K.; Sun, X. W. Adv. Funct. Mater. 2016, 26, 4595.

(14) Sutherland, B. R; Sargent, E. H. Nat. Photonics 2016, 10 (5), 295-302.

(15) Tian, Y.; Merdasa, A.; Peter, M.; Abdellah, M.; Zheng, K.; Ponseca, C. S.; Pullerits, T.; Yartsev, A.; Sundström, V.; Scheblykin, I. G. Nano Lett. 2015, 15 (3), 1603-1608.

(16) Park, Y. S.; Guo, S.; Makarov, N. S.; Klimov, V. I. ACS Nano 2015, 9 (10), 10386-10393.

(17) Swarnkar, A.; Chulliyil, R.; Ravi, V. K.; Irfanullah, M.; Chowdhury, A.; Nag, A. Angew. Chem., Int. Ed. 2015, 54 (51), 15424-15428.

(18) Hu, F.; Zhang, H.; Sun, C.; Yin, C.; Lv, B.; Zhang, C.; Yu, W. W.; Wang, X.; Zhang, Y.; Xiao, M. ACS Nano 2015, 9 (12), 1241012416.

(19) Makarov, N. S.; Guo, S.; Isaienko, O.; Liu, W.; Robel, I.; Klimov, V. I. Nano Lett. 2016, 16 (4), 2349-2362.

(20) Rainò, G.; Nedelcu, G.; Protesescu, L.; Bodnarchuk, M. I.; Kovalenko, M. V.; Mahrt, R. F.; Stöferle, T. ACS Nano 2016, 10 (2), 2485-2490.

(21) Akkerman, Q. A.; D’Innocenzo, V.; Accornero, S.; Scarpellini, A.; Petrozza, A.; Prato, M.; Manna, L. J. Am. Chem. Soc. 2015, 137 (32), 10276-10281.

(22) Nedelcu, G.; Protesescu, L.; Yakunin, S.; Bodnarchuk, M. I.; Grotevent, M. J.; Kovalenko, M. V. Nano Lett. 2015, 15 (8), 56355640.

(23) Zhang, D.; Yang, Y.; Bekenstein, Y.; Yu, Y.; Gibson, N. A.; Wong, A. B.; Eaton, S. W.; Kornienko, N.; Kong, Q.; Lai, M.; Alivisatos, A. P.; Leone, S. R.; Yang, P. J. Am. Chem. Soc. 2016, 138 (23), 7236-7239.
(24) Ramasamy, P.; Lim, D. H.; Kim, B.; Lee, S. H.; Lee, M. S.; Lee, J. S. Chem. Commun. 2016, 52 (10), 2067-2070.

(25) Palazon, F.; Akkerman, Q. A.; Prato, M.; Manna, L. ACS Nano 2016, 10 (1), 1224-1230.

(26) Zhang, D.; Eaton, S. W.; Yu, Y.; Dou, L.; Yang, P. J. Am. Chem. Soc. 2015, 137 (29), 9230-9233.

(27) Bekenstein, Y.; Koscher, B. A.; Eaton, S. W.; Yang, P.; Alivisatos, A. P. J. Am. Chem. Soc. 2015, 137 (51), 16008-16011.

(28) Akkerman, Q. A.; Motti, S. G.; Srimath Kandada, A. R.; Mosconi, E.; D’Innocenzo, V.; Bertoni, G.; Marras, S.; Kamino, B. A.; Miranda, L.; De Angelis, F.; Petrozza, A.; Prato, M.; Manna, L. J. Am. Chem. Soc. 2016, 138 (3), 1010-1016.

(29) Sun, S.; Yuan, D.; Xu, Y.; Wang, A.; Deng, Z. ACS Nano 2016, 10 (3), 3648-3657.

(30) Shamsi, J.; Dang, Z.; Bianchini, P.; Canale, C.; Stasio, F. D.; Brescia, R.; Prato, M.; Manna, L. J. Am. Chem. Soc. 2016, 138 (23), $7240-7243$.

(31) Koolyk, M.; Amgar, D.; Aharon, S.; Etgar, L. Nanoscale 2016, 8 (12), 6403-6409.

(32) Lignos, I.; Stavrakis, S.; Nedelcu, G.; Protesescu, L.; deMello, A. J.; Kovalenko, M. V. Nano Lett. 2016, 16 (3), 1869-1877.

(33) Chen, X.; Peng, L.; Huang, K.; Shi, Z.; Xie, R.; Yang, W. Nano Res. 2016, 9, 1994.

(34) Kim, Y.; Yassitepe, E.; Voznyy, O.; Comin, R.; Walters, G.; Gong, X.; Kanjanaboos, P.; Nogueira, A. F.; Sargent, E. H. ACS Appl. Mater. Interfaces 2015, 7 (45), 25007-25013.

(35) De Roo, J.; Ibáñez, M.; Geiregat, P.; Nedelcu, G.; Walravens, W.; Maes, J.; Martins, J. C.; Van Driessche, I.; Kovalenko, M. V.; Hens, Z. ACS Nano 2016, 10 (2), 2071-2081.

(36) Huang, H.; Chen, B.; Wang, Z.; Hung, T. F.; Susha, A. S.; Zhong, H.; Rogach, A. L. Chem. Sci. 2016, 7, 5699.

(37) Guo, Y.; Shoyama, K.; Sato, W.; Nakamura, E. Adv. Energy Mater. 2016, 6, (6), in press.

(38) Zhang, X.; Lv, L.; Ji, L.; Guo, G.; Liu, L.; Han, D.; Wang, B.; Tu, Y.; Hu, J.; Yang, D.; Dong, A. J. Am. Chem. Soc. 2016, 138 (10), 32903293.

(39) Schmidt, L. C.; Pertegás, A.; González-Carrero, S.; Malinkiewicz, O.; Agouram, S.; Mínguez Espallargas, G.; Bolink, H. J.; Galian, R. E.; Pérez-Prieto, J. J. Am. Chem. Soc. 2014, 136 (3), 850-853.

(40) Gonzalez-Carrero, S.; Galian, R. E.; Perez-Prieto, J. J. Mater. Chem. A 2015, 3 (17), 9187-9193.

(41) Horváth, E.; Spina, M.; Szekrényes, Z.; Kamarás, K.; Gaal, R.; Gachet, D.; Forró, L. Nano Lett. 2014, 14 (12), 6761-6766.

(42) Zhang, F.; Zhong, H.; Chen, C.; Wu, X.-g.; Hu, X.; Huang, H.; Han, J.; Zou, B.; Dong, Y. ACS Nano 2015, 9 (4), 4533-4542.

(43) Tyagi, P.; Arveson, S. M.; Tisdale, W. A. J. Phys. Chem. Lett. 2015, 6 (10), 1911-1916.

(44) Gonzalez-Carrero, S.; Espallargas, G. M.; Galian, R. E.; PerezPrieto, J. J. Mater. Chem. A 2015, 3 (26), 14039-14045.

(45) Jang, D. M.; Park, K.; Kim, D. H.; Park, J.; Shojaei, F.; Kang, H. S.; Ahn, J. P.; Lee, J. W.; Song, J. K. Nano Lett. 2015, 15 (8), 51915199.

(46) Huang, H.; Susha, A. S.; Kershaw, S. V.; Hung, T. F.; Rogach, A. L. Adv. Sci. 2015, 2, (9), in press.

(47) Wong, A. B.; Lai, M.; Eaton, S. W.; Yu, Y.; Lin, E.; Dou, L.; Fu, A.; Yang, P. Nano Lett. 2015, 15 (8), 5519-5524.

(48) Sichert, J. A.; Tong, Y.; Mutz, N.; Vollmer, M.; Fischer, S.; Milowska, K. Z.; García Cortadella, R.; Nickel, B.; Cardenas-Daw, C.; Stolarczyk, J. K.; Urban, A. S.; Feldmann, J. Nano Lett. 2015, 15 (10), 6521-6527.

(49) Dou, L.; Wong, A. B.; Yu, Y.; Lai, M.; Kornienko, N.; Eaton, S. W.; Fu, A.; Bischak, C. G.; Ma, J.; Ding, T.; Ginsberg, N. S.; Wang, L.W.; Alivisatos, A. P.; Yang, P. Science 2015, 349 (6255), 1518-1521.

(50) Hassan, Y.; Song, Y.; Pensack, R. D.; Abdelrahman, A. I.; Kobayashi, Y.; Winnik, M. A.; Scholes, G. D. Adv. Mater. 2016, 28 (3), 566-573.

(51) Vybornyi, O.; Yakunin, S.; Kovalenko, M. V. Nanoscale 2016, 8 (12), 6278-6283. 
(52) Huang, S.; Li, Z.; Kong, L.; Zhu, N.; Shan, A.; Li, L. J. Am. Chem. Soc. 2016, 138 (18), 5749-5752.

(53) Aharon, S.; Etgar, L. Nano Lett. 2016, 16 (5), 3230-3235.

(54) Hines, M. A.; Guyot-Sionnest, P. J. Phys. Chem. 1996, 100 (2), $468-471$.

(55) Cao, Y.-W.; Banin, U. Angew. Chem., Int. Ed. 1999, 38 (24), 3692-3694.

(56) Mićić, O. I.; Smith, B. B.; Nozik, A. J. J. Phys. Chem. B 2000, 104 (51), 12149-12156.

(57) Burschka, J.; Pellet, N.; Moon, S.-J.; Humphry-Baker, R.; Gao, P.; Nazeeruddin, M. K.; Gratzel, M. Nature 2013, 499 (7458), 316319.

(58) Lee, M. M.; Teuscher, J.; Miyasaka, T.; Murakami, T. N.; Snaith, H. J. Science 2012, 338 (6107), 643-647.

(59) Research Cell Efficiency Records. http://www.Nrel.Gov/Ncpv/ Images/Efficiency_Chart.Jpg (accessed May 2016).

(60) Noh, J. H.; Im, S. H.; Heo, J. H.; Mandal, T. N.; Seok, S. I. Nano Lett. 2013, 13 (4), 1764-1769.

(61) Dong, Q.; Fang, Y.; Shao, Y.; Mulligan, P.; Qiu, J.; Cao, L.; Huang, J. Science 2015, 347 (6225), 967-970.

(62) Shi, D.; Adinolfi, V.; Comin, R.; Yuan, M.; Alarousu, E.; Buin, A.; Chen, Y.; Hoogland, S.; Rothenberger, A.; Katsiev, K.; Losovyj, Y.; Zhang, X.; Dowben, P. A.; Mohammed, O. F.; Sargent, E. H.; Bakr, O. M. Science 2015, 347 (6221), 519-522.

(63) Zhumekenov, A. A.; Saidaminov, M. I.; Haque, M. A.; Alarousu, E.; Sarmah, S. P.; Murali, B.; Dursun, I.; Miao, X.-H.; Abdelhady, A. L.; $\mathrm{Wu}, \mathrm{T}$.; Mohammed, O. F.; Bakr, O. M. ACS Energy Lett. 2016, 1, 3237.

(64) Hao, F.; Stoumpos, C. C.; Chang, R. P. H.; Kanatzidis, M. G. J. Am. Chem. Soc. 2014, 136 (22), 8094-8099.

(65) Manser, J. S.; Christians, J. A.; Kamat, P. V. Chem. Rev. 2016, DOI: 10.1021/acs.chemrev.6b00136.

(66) Walsh, A.; Scanlon, D. O.; Chen, S.; Gong, X. G.; Wei, S.-H. Angew. Chem. 2015, 127 (6), 1811-1814.

(67) Quarti, C.; Mosconi, E.; De Angelis, F. Chem. Mater. 2014, 26 (22), 6557-6569.

(68) Bakulin, A. A.; Selig, O.; Bakker, H. J.; Rezus, Y. L. A.; Müller, C.; Glaser, T.; Lovrincic, R.; Sun, Z.; Chen, Z.; Walsh, A.; Frost, J. M.; Jansen, T. L. C. J. Phys. Chem. Lett. 2015, 6 (18), 3663-3669.

(69) Brivio, F.; Frost, J. M.; Skelton, J. M.; Jackson, A. J.; Weber, O. J.; Weller, M. T.; Goñi, A. R.; Leguy, A. M. A.; Barnes, P. R. F.; Walsh, A. Phys. Rev. B: Condens. Matter Mater. Phys. 2015, 92 (14), 144308.

(70) Yang, T.-Y.; Gregori, G.; Pellet, N.; Grätzel, M.; Maier, J. Angew. Chem., Int. Ed. 2015, 54 (27), 7905-7910.

(71) Leguy, A. M. A.; Frost, J. M.; McMahon, A. P.; Sakai, V. G.; Kochelmann, W.; Law, C.; Li, X.; Foglia, F.; Walsh, A.; O’Regan, B. C.; Nelson, J.; Cabral, J. T.; Barnes, P. R. F. Nat. Commun. 2015, 6, 7124.

(72) Mosconi, E.; De Angelis, F. ACS Energy Lett. 2016, 1, 182-188.

(73) Brandt, R. E.; Stevanović, V.; Ginley, D. S.; Buonassisi, T. MRS Commun. 2015, 5 (02), 265-275.

(74) Zakutayev, A.; Caskey, C. M.; Fioretti, A. N.; Ginley, D. S.; Vidal, J.; Stevanovic, V.; Tea, E.; Lany, S. J. Phys. Chem. Lett. 2014, 5 (7), 1117-1125.

(75) Berry, J.; Buonassisi, T.; Egger, D. A.; Hodes, G.; Kronik, L.; Loo, Y.-L.; Lubomirsky, I.; Marder, S. R.; Mastai, Y.; Miller, J. S.; Mitzi, D. B.; Paz, Y.; Rappe, A. M.; Riess, I.; Rybtchinski, B.; Stafsudd, O.; Stevanovic, V.; Toney, M. F.; Zitoun, D.; Kahn, A.; Ginley, D.; Cahen, D. Adv. Mater. 2015, 27 (35), 5102-5112.

(76) Ganose, A. M.; Butler, K. T.; Walsh, A.; Scanlon, D. O. J. Mater. Chem. A 2016, 4 (6), 2060-2068.

(77) Pandey, M.; Rasmussen, F. A.; Kuhar, K.; Olsen, T.; Jacobsen, K. W.; Thygesen, K. S. Nano Lett. 2016, 16 (4), 2234-2239.

(78) Fioretti, A. N.; Schwartz, C. P.; Vinson, J.; Nordlund, D.; Prendergast, D.; Tamboli, A. C.; Caskey, C. M.; Tuomisto, F.; Linez, F.; Christensen, S. T.; Toberer, E. S.; Lany, S.; Zakutayev, A. J. Appl. Phys. 2016, 119 (18), 181508.

(79) Shi, H.; Ming, W.; Du, M.-H. Phys. Rev. B: Condens. Matter Mater. Phys. 2016, 93 (10), 104108.

(80) Zakutayev, A. J. Mater. Chem. A 2016, 4 (18), 6742-6754.
(81) Kojima, A.; Ikegami, M.; Teshima, K.; Miyasaka, T. Chem. Lett. 2012, 41 (4), 397-399.

(82) Longo, G.; Pertegas, A.; Martinez-Sarti, L.; Sessolo, M.; Bolink, H. J. J. Mater. Chem. C 2015, 3 (43), 11286-11289.

(83) Klein, J. D.; Herrick, R. D.; Palmer, D.; Sailor, M. J.; Brumlik, C. J.; Martin, C. R. Chem. Mater. 1993, 5 (7), 902-904.

(84) Martin, C. R. Science 1994, 266 (5193), 1961-1966.

(85) Li, Y.; Xu, D.; Zhang, Q.; Chen, D.; Huang, F.; Xu, Y.; Guo, G.; Gu, Z. Chem. Mater. 1999, 11 (12), 3433-3435.

(86) Agger, J. R.; Anderson, M. W.; Pemble, M. E.; Terasaki, O.; Nozue, Y. J. Phys. Chem. B 1998, 102 (18), 3345-3353.

(87) Moller, K.; Bein, T. Chem. Mater. 1998, 10 (10), 2950-2963.

(88) Hirai, T.; Okubo, H.; Komasawa, I. J. Phys. Chem. B 1999, 103 (21), 4228-4230.

(89) Parala, H.; Winkler, H.; Kolbe, M.; Wohlfart, A.; Fischer, R. A.; Schmechel, R.; von Seggern, H. Adv. Mater. 2000, 12 (14), 10501055.

(90) RoHS Evaluations. QD Television Benchmarking. http://rohs. exemptions.oeko.info/fileadmin/user upload/RoHS Pack_10/Cd QD_Exs_QD_Vision_e_QD_Television_Benchmarking.pdf (accessed June 2016).

(91) Nanograde. Cadmium-Free Quantum Dot LCD Backlight Films for Medium- and Low-Priced LCD Displays. http://www.azonano. com/article.aspx?ArticleID=4168 (accessed June 2016).

(92) Pickett, N. In Cadmium-Free Quantum Dots for Display Applications, Presented at the Display Innovation China 2015, Beijing, China, October 13, 2015.

(93) Lee, Y.-C.; Tu, S.-H. Improving the Light-Emitting Efficiency of GaN LEDs Using Nanoimprint Lithography, Recent Advances in Nanofabrication Techniques and Applications; INTECH Open Access Publisher: Rijeka, Croatia, 2011. 